(c) American Dairy Science Association, 2004.

\title{
Relationship of Test-Day Somatic Cell Score with Test-Day and Lactation Milk Yields
}

\author{
R. H. Miller, H. D. Norman, G. R. Wiggans, and J. R. Wright \\ Animal Improvement Programs Laboratory, \\ Agricultural Research Service, USDA, Beltsville, MD 20705-2350
}

\begin{abstract}
To determine the relationship of test-day (TD) somatic cell score (SCS) to TD and lactation milk yields, 1,320,590 records from Holstein first and second calvings from 1995 through 2002 were examined. All lactations had recorded yield and SCS for at least the first 4 TD. Least square analyses were conducted for yields on TD 2 through 10 within herd and cow. The model included regressions on current TD SCS and mean SCS of all previous TD with separate estimates by parity; effects for parity and calving year were included as well as regression on days in milk on TD 1 . Corresponding analyses were conducted without regression on current SCS. An analysis of lactation yield was performed with a similar model and regression on all TD SCS. The SCS was highest most often on TD 1 for parity $1(22.5 \%)$ and on TD 10 for parity 2 (18.5\%). Regression of TD milk yield on mean of previous TD SCS was highest during the latter half of lactation (maximum of $-0.346 \mathrm{~kg} / \mathrm{SCS}$ unit on TD 9) for parity 1 and during TD through 7 (maximum of -0.366 $\mathrm{kg} / \mathrm{SCS}$ unit on TD 4) for parity 2. Regression of TD yield on current TD SCS tended to be larger for later lactation. Regression of lactation yield on TD SCS was negative and important for TD 1 through 6 for parity 1 and for all TD for parity 2. To minimize milk loss, mastitis control is most important immediately preand postcalving for parity 1 and throughout lactation for parity 2 .
\end{abstract}

(Key words: somatic cell score, test-day, milk yield)

Abbreviation key: TD = test-day.

\section{INTRODUCTION}

Efforts to decrease SCC in milk are encouraged. Although all milk contains somatic cells, SCC is a key measure of milk quality and severity of udder infections. Currently, bulk tank milk must have an SCC

Received September 15, 2003.

Accepted December 17, 2003.

Corresponding author: R. H. Miller; e-mail: millerrh@juno.com. of $<750,000$ cells $/ \mathrm{mL}$ to be legally marketable in the United States. In European Union countries, the limit has been lowered to 400,000 cells/mL. In many US markets, milk price premiums are paid for milk with low SCC; in some cases, high SCC milk is penalized (Fetrow et al., 2000).

Producers in DHI programs are encouraged to utilize SCC results for individual cows in mastitis control. As of January 1, 2003, 93\% of DHI cows are enrolled in SCC testing. Although many factors influence SCC, variation in SCC is thought to be primarily a result of clinical and subclinical bacterial infections of mammary quarters (Afifi, 1967; Bodoh et al., 1976; Coffey et al., 1986). Some researchers (e.g., Emanuelson et al., 1988) have reported a low phenotypic correlation between SCC and clinical mastitis, which may be because SCC is significantly influenced by the incidence of subclinical mastitis and because infections by environmental pathogens have short duration. In addition, a negative correlation between SCC and milk yield has been found for cows that were currently uninfected (Lindstrom and Syvajarvi, 1978; Miller et al., 1983).

Shook and co-workers (Shook, 1982; Shook and Bringe, 1987) proposed expressing SCC on a log (base 2) scale, which would result in a more normalized distribution. A further advantage of expressing SCC as SCS is that regression of milk yield on SCS is essentially linear in contrast to the relationship of yield with SCC. The negative relationship between SCS and milk yield has been referred to as "milk loss" and is a key tool in mastitis educational programs. Raubertas and Shook (1982) estimated that each unit increase in lactation SCS was associated with losses of 91 and $181 \mathrm{~kg}$ of milk during parities 1 and 2, respectively. Other researchers (Fetrow et al., 1991) reported similar estimates for milk loss. Only Jones et al. (1984) have examined milk loss associated with elevated SCS on test-day (TD).

Genetic evaluations of bulls for milk SCS were developed in the United States and have been provided to the dairy industry since 1994 (Schutz, 1994). Those evaluations were developed because of an antagonism between breeding values for milk yield and SCS, which 
suggests that selection for high yield reduces the ability of a cow to resist mastitis (Emanuelson et al., 1988).

The relationship between milk yield and SCC may overestimate true milk loss due to mastitis. When intramammary devices were inserted in the quarters of Israeli Friesians, clinical mastitis was reduced by about $70 \%$, but lactation milk yield exceeded that of controls by only $148 \mathrm{~kg}$, in part because cows with intramammary devices had shorter lactations (Miller et al., 1986). Three important aspects in regard to interpretation of the relationship between milk yield and SCC are 1) interpretation of variation among SCC at low levels, 2) presence of a "dilution effect" because of relatively constant SCC throughout lactation if no infection is present, and 3) compensation by uninfected quarters for mastitic quarters.

Although differences in SCC of $>500,000$ cells $/ \mathrm{mL}$ are widely accepted as indicating the severity of current mastitis infections, the interpretation of variations at low levels $(<125,000$ cells $/ \mathrm{mL})$ is less clear. Although milk yield decreases as low-level SCC increases, bulk milk with SCC of $<125,000$ cells $/ \mathrm{mL}$ is considered to be normal and even of high quality. The ability of testing equipment to distinguish variation in SCC at low levels also has been questioned (Faust and Timms, 1995).

Several researchers (Raubertas and Shook, 1982; Miller et al., 1983, 1993; Emanuelson and Persson, 1984; Miller et al., 1993) have discussed whether the relationship between milk yield and SCC partly may be an artifact due to a dilution effect: a short-term decrease in milk production could cause an increased somatic cell concentration because a relatively constant number of cells was being secreted into the milk over the lactation. In DHI milk-recording programs, the milk weight and the sample used for SCC determination both originate from the same milking. Miller et al. (1993) compared milk yield with SCC from prior milkings and found that the relationship between milk yield and SCC was present but to a lesser degree than with measurements derived from the same milking. Mastitis infections would be expected to continue to affect milk yield later in lactation if milk secretory tissue had been damaged and milk secreting cells had ceased to function. The monthly interval between DHI TD makes questionable whether such residual effects can be detected because some infections (especially by coliforms) can occur and completely disappear between 2 adjacent TD.

The goal of this study was to determine how SCS on current and previous TD is related to milk yield on current and subsequent TD and to lactation yield. Knowledge of those relationships should indicate whether elevated SCC during early lactation have a continuing impact on TD milk yield $\geq 30 \mathrm{~d}$ later and whether a dilution effect exists. Because yield levels and management practices have changed greatly during the past $20 \mathrm{yr}$, answers to those questions are needed to confirm the usefulness of DHI SCS and to update and to interpret estimates of lactation milk loss.

\section{MATERIALS AND METHODS}

Holstein first and second lactations with at least 4 consecutive TD that had both milk yield and SCS reported were selected. Standardized (305-d, twice daily milking, mature-equivalent) lactation milk yield also was examined. Lactations with a first TD that was $>40 \mathrm{~d}$ after calving were excluded. Calvings were from 1995 through 2002. Total lactations initially available were 555,590 first and 534,300 second.

Nine least square analyses were conducted in which the dependent variables were milk yields for TD 2, 3, $\ldots, 10$. In the analysis of milk yield on TD n, SCS for TD 1 through $n$ were required to be $>0$. Due to earlier problems in reporting missing tests, DHI convention is to report SCS on a scale of 0.1 to 9.9 (Animal Improvement Programs Laboratory, 1999). The model included regressions on current TD SCS and on the unweighted mean of all previous TD SCS. Nuisance effects included parity, calving year, and regression of DIM on TD 1. A regression on number of days open also was included for TD 7 through 10. Herd and cow effects were absorbed; thus, only cows with information for both parities 1 and 2 contributed to the estimates and to residual degrees of freedom. Similar analyses were conducted with the same model but without regression on current TD SCS. Finally, to assess relative impact of TD SCS on lactation milk yield, a similar analysis was conducted with standardized lactation yield as the dependent variable and with partial regressions on all 10 TD SCS.

\section{RESULTS}

Means of current and previous mean TD SCS, milk yield, and DIM are in Table 1. Also, Table 1 includes the percentage of cows that reached their lactation peak SCS on a particular TD. For both parities, mean TD SCS was lowest on TD 2; SCS was highest on TD 1 for parity 1 and on TD 10 for parity 2 . Mean TD milk yield was highest on TD 3 for parity 1 and on TD 2 for parity 2. Peak SCS for the lactation occurred most often on TD 1 for parity 1 ; for parity 2 , lactation peak was most often on TD 10.

Within-cow correlations among TD SCS are in Table 2. As expected, correlations between TD decline the 
Table 1. Mean test-day SCS, milk yield, and DIM and percentage of Holstein cows that reached peak lactation SCS by parity. ${ }^{1}$

\begin{tabular}{|c|c|c|c|c|c|c|c|c|c|c|c|c|c|c|}
\hline \multirow{4}{*}{$\begin{array}{l}\text { Test- } \\
\text { day }\end{array}$} & \multicolumn{7}{|c|}{ Parity 1} & \multicolumn{7}{|c|}{ Parity 2} \\
\hline & \multicolumn{4}{|c|}{ SCS } & \multirow[b]{3}{*}{ Milk (kg) } & \multirow[b]{3}{*}{ DIM (d) } & \multirow{3}{*}{$\begin{array}{l}\text { Cows that } \\
\text { reached peak } \\
\text { lactation } \\
\text { SCS }(\%)\end{array}$} & \multicolumn{4}{|c|}{ SCS } & \multirow[b]{3}{*}{ Milk (kg) } & \multirow[b]{3}{*}{ DIM (d) } & \multirow{3}{*}{$\begin{array}{l}\text { Cows that } \\
\text { reached peak } \\
\text { lactation } \\
\text { SCS }(\%)\end{array}$} \\
\hline & \multicolumn{2}{|c|}{ Previous } & \multicolumn{2}{|c|}{ Current } & & & & \multicolumn{2}{|c|}{ Previous } & \multicolumn{2}{|c|}{ Current } & & & \\
\hline & Mean & SD & Mean & $\mathrm{SD}$ & & & & Mean & SD & Mean & SD & & & \\
\hline 1 & - & - & 3.18 & 1.81 & 26.9 & 20 & 22.5 & - & - & 2.96 & 1.93 & 36.4 & 21 & 14.9 \\
\hline 2 & 2.90 & 1.52 & 2.63 & 1.76 & 30.5 & 51 & 8.2 & 2.78 & 1.69 & 2.60 & 1.96 & 39.3 & 52 & 7.3 \\
\hline 5 & 2.79 & 1.35 & 2.78 & 1.76 & 29.4 & 145 & 7.9 & 2.84 & 1.51 & 3.02 & 1.90 & 34.3 & 145 & 7.6 \\
\hline 6 & 2.79 & 1.33 & 2.81 & 1.76 & 28.7 & 176 & 7.9 & 2.89 & 1.48 & 3.15 & 1.85 & 32.5 & 177 & 7.9 \\
\hline 7 & 2.80 & 1.32 & 2.85 & 1.75 & 27.9 & 207 & 8.0 & 2.95 & 1.44 & 3.27 & 1.79 & 30.7 & 208 & 8.4 \\
\hline 8 & 2.81 & 1.31 & 2.89 & 1.74 & 27.0 & 238 & 8.4 & 3.00 & 1.41 & 3.39 & 1.73 & 28.7 & 239 & 9.4 \\
\hline 9 & 2.83 & 1.29 & 2.94 & 1.72 & 25.9 & 270 & 9.3 & 3.06 & 1.38 & 3.51 & 1.67 & 26.5 & 271 & 11.6 \\
\hline 10 & 2.85 & 1.28 & 3.04 & 1.71 & 24.2 & 301 & 12.4 & 3.12 & 1.34 & 3.68 & 1.63 & 23.5 & 302 & 18.5 \\
\hline
\end{tabular}

${ }^{1}$ Mean lactation average SCS were 2.85 and 3.11 for parities 1 and 2, respectively. Mean lactation average standardized lactation milk yields were $10,757 \mathrm{~kg}$ and 10,482 $\mathrm{kg}$ for parities 1 and 2, respectively.

further apart in time they are. Maximum correlation between adjacent TD was 0.67 .

Coefficients for partial regression of TD milk yield on mean of all previous TD SCS and on current TD SCS are in Table 3. Standard errors (not shown) ranged from 0.010 to 0.017 . Also in Table 3 are standard partial regression coefficients (ordinary partial regressions multiplied by the ratio of the standard deviation of the independent variable to the standard deviation of the dependent variable). The standard partial regression expresses change in standard deviation units of the dependent variable per standard deviation change in the independent variable. The standard partial regressions in Table 3 and the corresponding t-statistics (Table 4) are more appropriate than regression coefficients for comparing relative importance of relationships among TD. Examination of the independent effects of current and previous TD SCS on TD milk yield indicated that standard partial regressions for mean of previous TD SCS were smaller than those for current TD SCS throughout lactation for parity 1 ( -0.061 vs. -0.115 for TD 10$)$. For parity 2, standard partial regressions for mean of previous TD SCS were largest in TD 4 through 7 (maximum -0.067), and decreased during late lactation (t-statistics nonsignificant for TD 10).

Regressions of TD milk yield on current TD SCS (Tables 3 and 4) differed greatly by parity. All regression coefficients were significant $(P<0.01)$ and were larger during later lactation. In general, regression coefficients for current TD SCS were greater than those for mean of previous TD SCS in both parities. However, the relative magnitude of regressions for current to those for mean of previous TD was substantially greater in parity 2 than in parity 1 .

To assess how well previous TD SCS alone predicted milk yield on current TD, analyses were performed with current TD SCS excluded from the model (Table 5). Standard errors (not shown) ranged from 0.009 to 0.014. Table 5 also shows error degrees of freedom for

Table 2. Within-cow correlations among test-day SCS.

\begin{tabular}{|c|c|c|c|c|c|c|c|c|c|}
\hline \multirow[b]{2}{*}{ Test-day } & \multicolumn{9}{|c|}{ Test-day } \\
\hline & 2 & 3 & 4 & 5 & 6 & 7 & 8 & 9 & 10 \\
\hline 1 & 0.48 & 0.40 & 0.35 & 0.32 & 0.29 & 0.27 & 0.25 & 0.24 & 0.21 \\
\hline 2 & & 0.59 & 0.52 & 0.46 & 0.43 & 0.39 & 0.37 & 0.34 & 0.32 \\
\hline 3 & & & 0.62 & 0.56 & 0.51 & 0.47 & 0.43 & 0.41 & 0.37 \\
\hline 4 & & & & 0.64 & 0.59 & 0.54 & 0.50 & 0.46 & 0.42 \\
\hline 5 & & & & & 0.66 & 0.60 & 0.55 & 0.51 & 0.47 \\
\hline 6 & & & & & & 0.66 & 0.61 & 0.56 & 0.51 \\
\hline 7 & & & & & & & 0.67 & 0.62 & 0.56 \\
\hline 8 & & & & & & & & 0.67 & 0.61 \\
\hline 9 & & & & & & & & & 0.66 \\
\hline
\end{tabular}


Table 3. Partial and standard partial regressions ${ }^{1}$ of current test-day milk yield on previous test-day SCS and current test-day SCS by parity. ${ }^{2}$

\begin{tabular}{|c|c|c|c|c|c|c|c|c|}
\hline \multirow{4}{*}{$\begin{array}{l}\text { Current } \\
\text { test-day }\end{array}$} & \multicolumn{8}{|c|}{ Regression coefficient } \\
\hline & \multicolumn{4}{|c|}{ Parity 1} & \multicolumn{4}{|c|}{ Parity 2} \\
\hline & \multicolumn{2}{|c|}{ Previous } & \multicolumn{2}{|c|}{ Current } & \multicolumn{2}{|c|}{ Previous } & \multicolumn{2}{|c|}{ Current } \\
\hline & Reg & SP Reg & Reg & SP Reg & Reg & SP Reg & Reg & SP Reg \\
\hline $2^{3}$ & -0.142 & -0.023 & -0.235 & -0.043 & -0.289 & -0.047 & -0.589 & -0.114 \\
\hline 3 & -0.155 & -0.027 & -0.216 & -0.047 & -0.327 & -0.056 & -0.512 & -0.112 \\
\hline 4 & -0.163 & -0.030 & -0.252 & -0.060 & -0.366 & -0.066 & -0.489 & -0.117 \\
\hline 5 & -0.197 & -0.038 & -0.260 & -0.067 & -0.335 & -0.064 & -0.521 & -0.135 \\
\hline 6 & -0.249 & -0.051 & -0.255 & -0.071 & -0.329 & -0.067 & -0.569 & -0.159 \\
\hline 7 & -0.284 & -0.061 & -0.246 & -0.073 & -0.312 & -0.067 & -0.647 & -0.192 \\
\hline 8 & -0.295 & -0.065 & -0.291 & -0.090 & -0.269 & -0.060 & -0.744 & -0.231 \\
\hline 9 & -0.346 & -0.077 & -0.286 & -0.089 & -0.198 & -0.044 & -0.875 & -0.273 \\
\hline 10 & -0.302 & -0.061 & -0.401 & -0.115 & $0.021(\mathrm{NS})$ & 0.004 & -1.209 & -0.348 \\
\hline
\end{tabular}

${ }^{1}$ Model was fitted within herd-cow for cows with information on both parities 1 and 2; all partial regression coefficients were significant $(P<0.01)$ unless designated as nonsignificant (NS).

${ }^{2}$ Partial regression coefficients are expressed as kg milk per unit SCS; standard partials are expressed as standard deviation units of test-day milk per standard deviation of SCS.

${ }^{3}$ For test-day 2 , mean of previous test-day SCS = test-day 1 SCS.

Table 4. $t$-Statistics for regression ${ }^{1}$ of current test-day milk yield on mean of previous test-day SCS and on current test-day SCS by parity.

\begin{tabular}{lllll}
\hline & \multicolumn{3}{c}{$t$-Statistic } \\
\cline { 2 - 5 } Current & Parity 1 & \multicolumn{2}{c}{ Parity 2} \\
\cline { 2 - 5 } test-day & Previous & Current & Previous & Current \\
\hline $2^{2}$ & -13.44 & -21.70 & -28.56 & -59.80 \\
3 & -12.09 & -19.55 & -27.86 & -51.28 \\
4 & -11.89 & -22.74 & -29.79 & -48.90 \\
5 & -13.55 & -22.93 & -25.72 & -50.65 \\
6 & -16.45 & -22.04 & -24.75 & -53.22 \\
7 & -17.69 & -20.26 & -22.05 & -56.71 \\
8 & -17.85 & -24.43 & -18.40 & -62.59 \\
9 & -20.07 & -22.04 & -12.86 & -69.46 \\
10 & -15.37 & -27.15 & 1.20 (NS) & -84.40 \\
\hline
\end{tabular}

${ }^{1}$ Model was fitted within herd-cow for cows with information for both parities 1 and 2 ; all $t$-statistics were significant $(P<0.01)$ unless designated as nonsignificant (NS).

${ }^{2}$ For test-day 2 , mean of previous test-day SCS = test-day 1 SCS.

Table 5. Regression, standard partial regression coefficients and $t$-statistics for regression ${ }^{1}$ of current testday milk yield on mean of previous test-day SCS by parity.

\begin{tabular}{|c|c|c|c|c|c|c|c|}
\hline \multirow{2}{*}{$\begin{array}{l}\text { Current } \\
\text { test-day }\end{array}$} & \multicolumn{3}{|c|}{ Parity 1} & \multicolumn{3}{|c|}{ Parity 2} & \multirow[b]{2}{*}{ Error df } \\
\hline & Reg (kg milk/SCS) & SP reg & $t$-Statistic & Reg (kg milk/SCS) & SP reg & $t$-Statistic & \\
\hline $2^{2}$ & -0.201 & -0.033 & -21.10 & -0.581 & -0.095 & -66.41 & 214,526 \\
\hline 3 & -0.256 & -0.044 & -23.66 & -0.664 & -0.114 & -69.66 & 213,672 \\
\hline 4 & -0.315 & -0.057 & -28.03 & -0.711 & -0.129 & -72.96 & 212,927 \\
\hline 5 & -0.371 & -0.071 & -31.74 & -0.713 & -0.136 & -70.68 & 203,369 \\
\hline 6 & -0.428 & -0.087 & -35.65 & -0.746 & -0.151 & -71.56 & 196,010 \\
\hline 7 & -0.462 & -0.099 & -36.09 & -0.784 & -0.168 & -69.87 & 176,296 \\
\hline 8 & -0.509 & -0.113 & -38.64 & -0.797 & -0.177 & -68.17 & 171,801 \\
\hline 9 & -0.550 & -0.122 & -39.63 & -0.805 & -0.179 & -64.53 & 165,397 \\
\hline 10 & -0.587 & -0.118 & -36.23 & -0.780 & -0.157 & -52.86 & 143,748 \\
\hline
\end{tabular}

${ }^{1}$ Model was fitted within herd-cow but without regression on current test-day SCS for cows with information for both parities 1 and 2; all regression coefficients were significant $(P<0.01)$.

${ }^{2}$ For test-day 2 , mean of previous test-day SCS = test-day 1 SCS. 
Table 6. Coefficients and $t$-statistics for partial regression of standardized $^{1}$ lactation milk yield (adjusted for days open) on test-day SCS by parity.

\begin{tabular}{lllllc}
\hline & \multicolumn{2}{c}{ Parity 1} & & \multicolumn{2}{c}{ Parity 2} \\
\cline { 2 - 3 } \cline { 5 - 6 } Test-day & $\begin{array}{l}\text { Regression coefficient } \\
\text { (kg milk/SCS unit) }\end{array}$ & $t$-Statistic & & $\begin{array}{l}\text { Regression coefficient } \\
\text { (kg milk/SCS unit) }\end{array}$ & $t$-Statistic \\
\hline 1 & -54.6 & $-22.4^{* *}$ & & -61.4 & $-26.0^{* *}$ \\
2 & -40.9 & $-14.2^{* *}$ & & -32.3 & $-12.3^{* *}$ \\
3 & -31.4 & $-10.2^{* *}$ & & -25.3 & $-9.2^{* *}$ \\
4 & -15.3 & $-4.8^{* *}$ & -16.9 & $-5.8^{* *}$ \\
5 & -9.4 & $-2.9^{* *}$ & -13.7 & $-4.5^{* *}$ \\
6 & -7.2 & $-2.2^{*}$ & -18.2 & $-5.7^{* *}$ \\
7 & -0.7 & $-0.2(\mathrm{NS})$ & -18.0 & $-5.5^{* *}$ \\
8 & -6.5 & $-1.9(\mathrm{NS})$ & -21.5 & $-6.4^{* *}$ \\
9 & 11.6 & $3.4^{* *}$ & -20.8 & $-6.1^{* *}$ \\
10 & 15.7 & $4.9^{* *}$ & -45.3 & $-14.3^{* *}$ \\
\hline
\end{tabular}

${ }^{1}$ Lactation milk yield standardized to a $305-\mathrm{d}$, twice daily milking, mature-equivalent basis.

$* P<0.05$.

$* * P<0.01$.

each TD analysis. The regressions in Table 5 are larger than those in Table 3 because they include correlated as well as independent effects. For parity 1, standard partial regressions were largest for TD 9 and 10. For parity 2 , standard partial regressions were largest for TD 7 through 10. Standard partial regression coefficients were consistently larger for parity 2 than for parity 1 (TD milk was not age adjusted), and also were larger for the second half of lactation than for first half in both parities.

Partial regression coefficients of standardized lactation milk yield on TD SCS for cows with information for both parities 1 and 2 and a TD SCS for all 10 TD are shown in Table 6.

In Table 6, for example, if SCS on TD 2 through 10 are held constant, an increase of one SCS unit on TD 1 would result in a $54.6 \mathrm{~kg}$ loss in first-lactation milk yield; in second lactation, a loss of $61.4 \mathrm{~kg}$ would result. Standard partial regressions (not shown) ranged from -0.076 (TD 1) to 0.024 (TD 10) in first lactation and from -0.086 (TD 1) to -0.022 (TD 5) in second lactation. Standard partials ranked TD similarly to the t-statistics in Table 6.

Regression patterns across TD differed markedly between parities 1 and 2 . For parity 1 , regression coefficients were negative and significant $(P<0.05)$ for TD 1 through 6 , negative and nonsignificant $(P \geq 0.01)$ for TD 7 and 8 , and positive and significant $(P<0.01)$ for TD 9 and 10. For parity 2 , regression coefficients were negative and significant $(P<0.01)$ for all 10 TD and ranged from $-61.4 \mathrm{~kg}$ of milk/SCS unit for TD 1 to $-13.7 \mathrm{~kg}$ of milk/SCS unit for TD 5. For both parities, largest negative impact on lactation yield was for TD 1. However, second largest impact was for TD 2 for parity 1 and for TD 10 for parity 2 .
To conform more closely to the estimates of Raubertas and Shook (1982), standardized lactation yield was regressed on mean of TD SCS for TD 1 to 10. Regression coefficients were $-125 \mathrm{~kg}$ of milk/SCS unit for parity 1 and $-266 \mathrm{~kg}$ of milk/SCS unit for parity 2 . The reduction in coefficient of determination when fitting mean TD SCS was less than $0.1 \%$ compared with fitting all 10 TD SCS simultaneously. Thus, the average of 10 tests contains nearly as much information as the 10 individual tests weighted differently.

\section{DISCUSSION AND CONCLUSIONS}

Elevated SCS on TD primarily impacted milk yield of the current TD. However, an elevated SCS on TD also had a carryover effect on milk yield of subsequent TD. The 2 milk yield losses were more similar for parity 1 than for parity 2 . Milk loss over an entire lactation is, therefore, a function of both the immediate and carryover effects of events that caused increased secretion of somatic cells into milk.

Current TD SCS and mean of previous TD SCS were significant independent predictors (Tables 3 and 4) of current TD milk yield. Regressions of TD milk on mean of previous TD SCS differed among stages of lactation for both parities. Standard partial regressions for mean of previous TD SCS increased during first lactation, to a maximum on TD 9; however, for parity 2, standard partial regression for previous TD SCS was maximum for TD 4 to 7, and was smallest for TD 10 .

When only mean of previous TD SCS was used to predict milk yield on next TD (Table 5), corresponding partial and standard partial regression coefficients were greater for parity 2 than for parity 1 , likely because TD milk yields were larger for parity 2 . For 
both parities, regressions for mean of previous TD SCS tended to increase throughout lactation as the amount of information provided by the mean increased with additional TD.

Just as observed for TD milk yields, the implications of an elevated TD SCS for lactation milk yield (Table 6) depended on lactation stage and parity. Because lactation yield had been adjusted to a mature-equivalent basis, higher mean production for parity 2 compared with parity 1 should not have influenced magnitude of differences in regression coefficients between parities 1 and 2 . The lactation stage at which peak SCS occurred differed between parities 1 and 2 (Table 1), and lactation peak SCS occurred most frequently on TD 1 for parity 1 and on TD 10 for parity 2 (second most frequent occurrence was on TD 1 ). The occurrence of a peak SCS during a lactation should primarily reflect the occurrence of new mastitis infections. Heringstad et al. (2003) reported that frequency of clinical mastitis was $18.5 \%$ through 120 DIM for parity 1 but reached only $23.3 \%$ by 300 DIM. Our results suggest that new infections were frequent around TD 1 for both parities 1 and 2, but that the frequency was also high around TD 10 for parity 2 .

Regression coefficients and t-statistics (Table 5) indicated that elevated SCS on TD 1 had the greatest negative impact on lactation milk yield regardless of parity. Mastitis infections during early lactation may damage milk secretory cells and thus have extended negative effects on cumulative milk yield. However, the implications of elevated SCS during late lactation were quite different between parities 1 and 2 . For parity 1 , an independent negative impact from elevated TD SCS did not occur after TD 6, and regression coefficients were positive for TD 9 and 10 . For parity 2, elevated TD SCS had a consistently negative impact on lactation milk yield, and regression of lactation yield on SCS for TD 10 (-45.3 $\mathrm{kg}$ of milk/SCS unit) was second in magnitude to that of TD $1(-61.4 \mathrm{~kg}$ of milk/SCS unit). The smallest independent impact on lactation yield for parity 2 was for TD $5(-13.7 \mathrm{~kg}$ of milk/SCS unit).

At what stage of lactation should an elevated SCS be expected to have the most serious consequences for cumulative milk yield? As anticipated, regression coefficients of lactation yield on TD SCS were large and negative for TD 1 because reduced activity of milk secretory cells during early lactation continues to depress milk yield. However, the large negative impact of elevated SCS on TD 10 for parity 2 was surprising because new infections that occur during late lactation impact yield for a shorter time, especially for a 305-d measure. The mean DIM on TD 10 was $301.9 \mathrm{~d}$ for parity 2 . Thus, many cows would have reached TD
10 after $305 \mathrm{~d}$. However, the current best prediction method of estimating 305-d yield makes use of tests beyond $305 \mathrm{~d}$ (VanRaden, 1997). If actual lactation milk yield had been available, the impact of an elevated SCS on TD 10 might have been greater (lactation mean DIM for parity 2 was $370 \mathrm{~d}$ ). To further investigate, an analysis was performed with only regression of lactation yield on SCS for TD 10. That regression was nonsignificant $(P \geq 0.01)$ for parity 1 but was $-132.7 \mathrm{~kg}$ of milk/SCS unit for parity 2 . Thus, the positive regression coefficients for TD 9 and 10 of parity 1 (Table 5) were probably artifacts, possibly because of colinearity.

Regressions for lactation yield on TD SCS were not derived from actual milk yield. Mean age at calving was 26.9 mo for parity 1 and 40.8 mo for parity 2 . The regressions can be converted approximately to a measure without age adjustment by multiplying the regression coefficients for parity 1 by 0.786 and those for parity 2 by 0.911 . When age adjustment was removed, regression coefficients ranged from $-42.8 \mathrm{~kg}$ of milk/SCS unit for TD 1 to $12.3 \mathrm{~kg}$ of milk/SCS unit for TD 10 for parity 1 and from $-55.9 \mathrm{~kg}$ of milk/SCS unit for TD 1 to $-16.4 \mathrm{~kg}$ of milk/SCS unit for TD 6 for parity 2; regression for TD 10 of parity 2 was $-41.3 \mathrm{~kg}$ of milk/SCS unit. The regression coefficients for ageadjusted milk yield (Table 6 ) were generally greater than coefficients without age adjustment for parity 2; however, when milk yield unadjusted for age was used, the overall ratio of parity 2 to parity 1 coefficients was even greater. Because 305-d milk yield was used, the true impact of elevated SCS on total lactation yield was probably greater than suggested by the regression coefficients in Table 6.

Our results are not directly comparable to those of Raubertas and Shook (1982), who reported that an increase of one unit in lactation mean SCS resulted in actual milk yield losses of $91 \mathrm{~kg}$ for parity 1 and $181 \mathrm{~kg}$ for parity 2. For Finnish Ayrshires (RajalaSchultz et al., 1999), total milk loss due to infection ranged from 110 to $552 \mathrm{~kg}$, depending on parity and lactation stage at mastitis infection.

Reducing episodes of clinical and subclinical mastitis reduces milk loss in 2 ways. The immediate depression of milk yield accompanying an ongoing infection is avoided (as well as reducing milk discarded because of antibiotic treatment), and the associated carryover effect on future milk production also is avoided. That carryover effect presumably results from long-term effects of infection on number or activity of milk secretory cells. Rajala-Schultz et al. (1999) reported that cows with clinical mastitis did not regain their premastitis milk yields during the remainder of lactation. 
The carryover effects of elevated SCS are of particular concern during early lactation for parity 1 . The most frequent lactation peak SCS on TD 1 for parity 1 may reflect an influx of mastitis infections in heifers prior to or just after first calving (mean DIM on TD 1 was 20.2 d). Nickerson et al. (1995) reported that nulliparous heifers frequently were infected before first calving. Recently, Oliver et al. (2003) showed that intramammary infusion of antibiotics prior to first calving of Jersey heifers reduced infections after calving and increased milk yield for parity 1 by $531 \mathrm{~kg}$ compared with controls.

There was an increased frequency of peak SCS during late lactation for both parities, but was much more pronounced for parity 2 . This suggests that while mastitis control is most critical for heifers around first calving, preventive regimes are more uniformly needed throughout lactation for parity 2 because resistance is expected to decline with age.

In addition to the carryover effect of elevated SCS within lactation, residual effects of an elevated SCS during a previous lactation may also exist for milk yield for a subsequent lactation. Raubertas and Shook (1982) did not find a carryover effect from parity 1 to 2 . Houben et al. (1993) reported that cows with 3 clinical quarters or more during first lactation had $381 \mathrm{~kg}$ less milk during second lactation. Fetrow et al. (1991) found that the effect of increased SCC during second lactation on third-lactation milk yield was significant $(P<0.04)$ but only 20 to $30 \%$ as large as the direct effect of SCC during third lactation.

Our results also have implications for the hypothesis of dilution effect, which assumes that decreases in milk yield caused by temporary factors (such as reduced feed intake) result in an increase in milk somatic cell concentration. In contrast to the regression of current TD milk yield on current TD SCS, the regression of TD yield on mean of previous TD SCS cannot reflect dilution effects.

Results for the impact of elevated SCS on lactation yield in this study agreed with those of earlier studies (Raubertas and Shook, 1982). Our regressions were 35 to $45 \%$ larger than those of Raubertas and Shook (1982). This may be because milk yields in the present data are about $50 \%$ higher than in the earlier study. Furthermore, our regression for parity 2 is about $50 \%$ larger than that for parity 1 , similar to the results of Raubertas and Shook (1982).

Regardless of premiums paid for bulk-tank milk with reduced cell count, substantial increases in milk yield occur when frequency of mastitis infections is reduced. In addition to reduced milk loss with decreased mastitis infections, labor costs, treatment re- quired, milk discarded, and culling due to mastitis all decrease.

\section{ACKNOWLEDGMENTS}

Suggestions by M. J. Paape (Immunology and Disease Resistance Laboratory, ARS, USDA, Beltsville, MD), G. W. Rogers (University of Tennessee, Knoxville), and G. E. Shook (University of Wisconsin, Madison) are gratefully acknowledged.

\section{REFERENCES}

Afifi, Y. A. 1967. Genetical and some environmental influences affecting the level of leucocyte counts in the milk of cows. Mededelingen Landbouwhogeschool Wageningen 67-11. Diss., Wageningen Univ., The Netherlands.

Animal Improvement Programs Laboratory. 1999. Listing of Format 4, Reference Note 75. Online (https://aipl.arsusda.gov/formats/ fmt4.html). Accessed December 9, 2003.

Bodoh, G. W., W. J. Battista, and L. H. Schultz. 1976. Variation in somatic cell counts in Dairy Herd Improvement milk samples. J. Dairy Sci. 59:1119-1123.

Coffey, E. M., W. E. Vinson, and R. E. Pearson. 1986. Potential of somatic cell concentration in milk as a sire selection criterion to reduce mastitis in dairy cattle. J. Dairy Sci. 69:2163-2172.

Emanuelson, U., B. Danell, and J. Philipsson. 1988. Genetic parameters for clinical mastitis, somatic cell counts, and milk production estimated by multiple-trait restricted maximum likelihood. J. Dairy Sci. 71:467-476.

Emanuelson, U., and E. Persson. 1984. Studies on somatic cell counts in milk from Swedish dairy cows. I. Non-genetic causes of variation in monthly test-day results. Acta Agric. Scand. 34:33-44.

Faust, M. A., and L. L. Timms. 1995. Estimates of variability for somatic cell count measurements in the Iowa dairy industry. J. Dairy Sci. 78:546-551.

Fetrow, J., D. Mann, K. Butcher, and B. McDaniel. 1991. Production losses from mastitis: Carry-over from the previous lactation. J. Dairy Sci. 74:833-839.

Fetrow, J., S. Stewart, S. Eicker, R. Farnsworth, and R. Bey. 2000. Mastitis: An economic consideration. Pages 3-47 in Proc. 39th Annu. Mtg. Natl. Mastitis Counc., Atlanta, GA. Natl. Mastitis Counc., Inc., Madison, WI.

Heringstad, B., R. Rekaya, D. Gianola, G. Klemetsdal, and K. A. Weigel. 2003. Bivariate analysis of liability to clinical mastitis and to culling in first-lactation cows. J. Dairy Sci. 86:653-660.

Houben, E. H. P., A. A. Dijkhuizen, J. A. M. Van Arendonk, and R. B. M. Huirne. 1993. Short- and long-term production losses and repeatability of clinical mastitis in dairy cattle. J. Dairy Sci. 76:2561-2578.

Jones, G. M., R. E. Pearson, G. A. Clabaugh, and C. W. Heald. 1984. Relationships between somatic cell counts and milk production. J. Dairy Sci. 67:1823-1831.

Lindstrom, U. B., and J. Syvajarvi. 1978. Use of field records in breeding for mastitis resistance in dairy cattle. Livest. Prod. Sci. $5: 29-44$.

Miller, R. H., U. Emanuelson, E. Persson, L. Brolund, J. Philipsson, and H. Funke. 1983. Relationships of milk somatic cell counts to daily milk yield and composition. Acta Agric. Scand. 33:209-223.

Miller, R. H., M. J. Paape, L. A. Fulton, and M. M. Schutz. 1993. The relationship of milk somatic cell count to milk yields of Holstein heifers after first calving. J. Dairy Sci. 76:728-733.

Miller, R. H., G. Ziv, M. J. Paape, and L. A. Fulton. 1986. Effect of presence of abraded intramammary device (AIMD) on lactation milk yield of Israeli Friesians. J. Dairy Sci. 69:201. (Abstr.)

Nickerson, S. C., W. E. Owen, and R. L. Boddie. 1995. Mastitis in dairy heifers: initial studies on prevalence and control. J. Dairy Sci. 78:1607-1618. 
Oliver, S. P., M. J. Lewis, B. E. Gillespie, H. H. Dowlen, E. C. Jaenicke, and R. K. Roberts. 2003. Prepartum antibiotic treatment of heifers: milk production, milk quality and economic benefit. J. Dairy Sci. 86:1187-1193.

Rajala-Schultz, P. J., Y. T. Grohn, C. E. McCullough, and C. L. Guard. 1999. Effects of clinical mastitis on milk yield in dairy cows. J. Dairy Sci. 82:1213-1220.

Raubertas, R. F., and G. E. Shook. 1982. Relationship between lactation measures of somatic cell concentration and milk yield. J. Dairy Sci. 65:419-425.
Schutz, M. M. 1994. Genetic evaluation of somatic cell scores for United States dairy cattle. J. Dairy Sci. 77:2113-2129.

Shook, G. E. 1982. Approaches to summarizing somatic cell counts which improve interpretability. Pages 150-166 in Proc. 21st Natl. Mastitis Counc. Natl. Mastitis Counc., Madison, WI.

Shook, G. E., and A. N. Bringe. 1987. The somatic cell count: A tool to reduce milk yield losses. Publ. A3391. Coop. Ext. Serv., Univ. Wisconsin, Madison.

VanRaden, P. M. 1997. Lactation yields and accuracies computed from test day yields and (co)variances by best prediction. J. Dairy Sci. 80:3015-3022. 